\title{
Performance Augmentation of V- Bladed Savonius Wind Turbine
}

\author{
A Vivek Anand, M Sathyanarayana Gupta, J Sahana, P Shanmuga Priya, V Hariprasad
}

\begin{abstract}
Fossil fuels, although an essential source of energy, have been a major cause for the degradation of the environment. The negative impacts created by these fossil fuels have forced mankind to adopt alternate measures for energy production. Renewable energy resources have been optimal in replacing the conventional energy sources as they are environmental friendly. Wind energy has been harnessed effectively all over the world for the production of electric power. Wind turbines extract the kinetic energy of the wind and convert it into mechanical energy and further convert it into electrical energy using generators. In this work, we have compared the performance of the Savonius turbine with five different blade designs. Initially, the flow around the different blade designs has been analyzed through computational fluid dynamics. Subsequently, the turbine blades were fabricated using light-weight materials like Aluminium sheet metal and tested in the low speed wind tunnel. The performance of the turbine has been characterized by measuring its rotational speed (in terms of RPM) and the amount of torque produced at different wind velocities. Based on the wind tunnel tests we were able to conclude that among the five blade designs, the V-shaped blade with an interior angle of 60 has the highest coefficient of power of 0.09 at $12.6 \mathrm{~m} / \mathrm{s}$.
\end{abstract}

Keywords : Coefficient of Power, Savonius Wind Turbine.

\section{INTRODUCTION}

The rising levels of carbon dioxide emissions, greenhouse gases and dramatic climate changes have forced governments all over the world to adopt clean and environmentally friendly technologies. Renewable energy sources are an effective alternative to conventional energy sources like fossil fuels, which have been deteriorating at an alarming rate. Solar, wind, hydro, tidal, geothermal and biomass are some of the popular renewable energies that

Revised Manuscript Received on December 30, 2019.

* Correspondence Author

A Vivek Anand*, Department of Aeronautical Engineering, MLR Institute of Technology, Hyderabad, India. Email: vivekanandbit@gmail.com

M Sathyanarayana Gupta, Department of Aeronautical Engineering, MLR Institute of Technology, Hyderabad, India. Email: msngupta.m@gmail.com

J Sahana, Department of Aeronautical Engineering, Bannari Amman Institute of Technology, Sathyamangalam, India. Email: sahanajawahar7@gmail.com

P ShanmugaPriya, Department of Aeronautical Engineering, Bannar Amman Institute of Technology, Sathyamangalam, India. Email: shanmugapriyaparimalanathan@gmail.com

V Hariprasad, Department of Aeronautical Engineering, Bannari Amman Institute of Technology, Sathyamangalam, India. Email:hari007aero@gmail.com

(C) The Authors. Published by Blue Eyes Intelligence Engineering and Sciences Publication (BEIESP). This is an open access article under the CC BY-NC-ND license (http://creativecommons.org/licenses/by-nc-nd/4.0/) power cities worldwide. In India, it has been estimated that renewable energy sources account for $12.5 \%$ of the overall production of power, which approximately estimates to 27.5 GW [1]. As of March 2013, the total installed capacity of wind energy was $19 \mathrm{GW}$ [1]. It has also been estimated that the amount of wind energy that is continuously available in India is approximately 10 million MW [2-5].

Wind turbines can be broadly classified as Horizontal Axis Wind Turbines (HAWT) and Vertical Axis Wind Turbines (VAWT) [6-11].The Savonius wind turbine is a VAWT that utilizes drag force for its operation. The conventional Savonius turbines consist of either two or three blades attached to a central shaft. The cross-sectional view of a single blade would look like the letter "C". Typically the blades form two or three vertical half cylinders that rotate due to the difference in the forces applied on each blade. The concave blade catches the wind and causes it to rotate about its vertical axis, whereas the convex blade deflects the wind that hits upon it and therefore experiences less drag as denoted in Figure 1. Due to the differential drag on the blades, the turbine starts to rotate.A number of studies have been conducted in order to determine the performance of the Savonius wind turbine based on the number of blades, number of stages, overlap ratio and aspect ratio. It has been concluded with experimental proof that the two-bladed Savonius wind turbine has the highest efficiency[12-20]. While increasing the number of stages from one to two, the coefficient of power increases, whereas on further increasing the number of stages from two to three there is a decrease in the coefficient of power. This is because of the increase in the inertia of the blades in the three-stage Savonius turbine [5] Experiments conducted by N. H. Mahmoud et al shows that turbine rotors without an overlap ratio perform better than the rotors with an overlap. The aspect ratio of the turbine blade is an important factor that influences its aerodynamic performance. Experimental results have concluded that with the increase in the aspect ratio, the power coefficient increases[6].

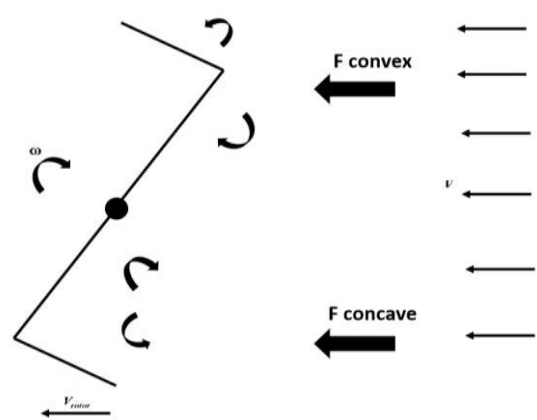

Fig. 1. Schematic sketch of the working of savonius turbine 


\section{Performance Augmentation of V- Bladed Savonius Wind Turbine}

\section{EXPERIMENTAL WORK}

\section{A. Fabrication of the Wind Turbine}

In order to ensure that the whole setup is lightweight, aluminium is used in the fabrication of the blades and the outer frame. The blades of the turbine are fabricated using an aluminium sheet of thickness $0.8 \mathrm{~mm}$. For the C-shaped two-bladed turbine (Figure 2a), the aluminium sheet is cut into two identical rectangles of $18 \mathrm{~cm} \mathrm{X} 14 \mathrm{~cm}$ dimension and bent to a diameter of $9 \mathrm{~cm}$ with a length of $18 \mathrm{~cm}$. The four-bladed triangular turbines (Figure $2 b$ ) are fabricated by cutting each of the rectangular sheets of dimensions $18 \mathrm{~cm} \mathrm{X}$ $14 \mathrm{~cm}$ into two right angle triangles and then bending them to a diameter of $9 \mathrm{~cm}$. For the $\mathrm{V}$-shaped two-bladed turbine, the aluminium sheet is cut into two identical squares with sides measuring $18 \mathrm{~cm}$ are then bent to form a V shape with an interior angle of $60^{\circ}, 90^{\circ}$ and $120^{\circ}$ (Figures c, d \& e). The blades of the turbine are attached to a mild steel shaft of diameter $10 \mathrm{~mm}$. This set up is then mounted on an aluminium frame with bearings on either side to aid in the smooth rotary motion.

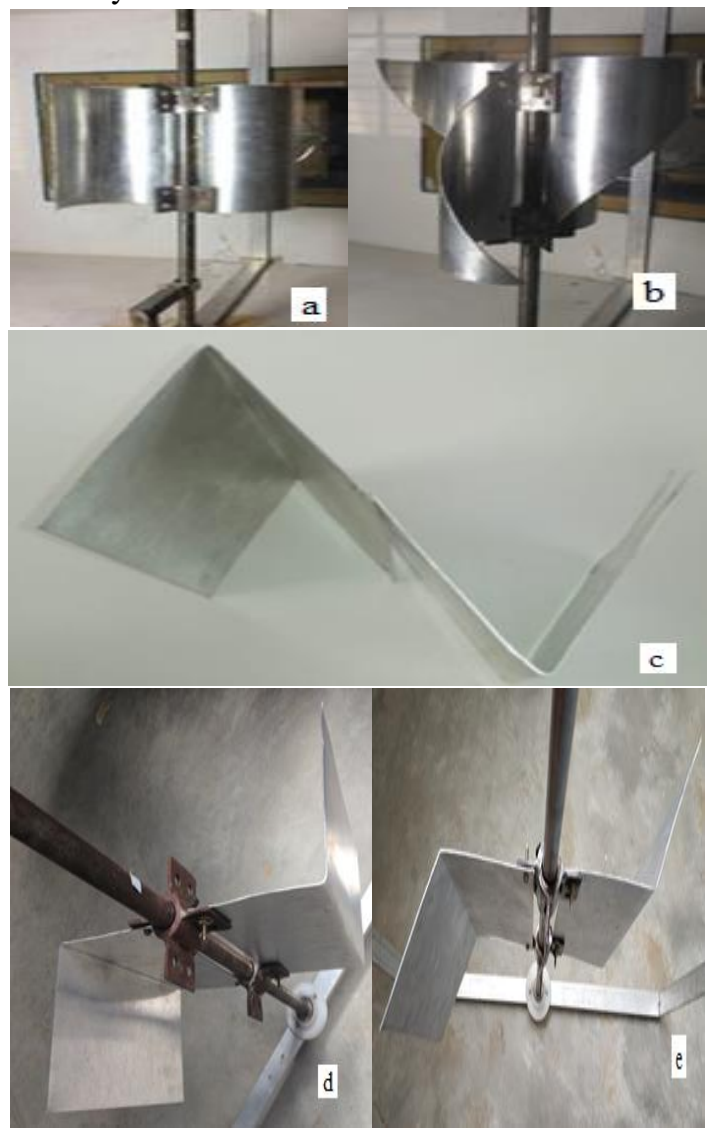

Fig. 2. Blade Designs (a) C-shaped blade, (b)

Triangular blade, (c) V-shaped $60^{\circ}$ blade, (d) V-shaped $90^{\circ}$ blade, (e) $\mathrm{V}$-shaped $120^{\circ}$ blade

\section{B. Flow Simulation of the Turbine Blades}

A two-dimensional computational flow simulation of the turbine blades has been performed in order to understand the behavior of air around the different cross-sections of the blades. This simulation was performed using Ansys R 15.0 software. Using the geometry module, the two-dimensional blade designs were created enclosed in a control volume. The geometries were the meshed finely using triangular and quad elements. A very fine mesh was created around the blade geometries in order to obtain accurate results. Since the designs have to be tested at low velocities, the pressure-based solver was used. The analysis was performed using the standard $k-\varepsilon$ viscous model. The inlets of the control volumes were set as velocity-inlets and the outlets were pressure-outlets with zero gauge pressure. The blades were analyzed at velocities at which they exhibited their peak performance.

\section{Velocity Contour}

It can be observed from the velocity contours of the C-shaped blade that on the inner side of the blade due to stagnation of the air flow, the velocity is drastically retarded when analyzed at an velocity of $7 \mathrm{~m} / \mathrm{s}$ (Figure 3a). On the contrary the flow at the tip of the blades is accelerated to a maximum of $15.3 \mathrm{~m} / \mathrm{s}$. The $\mathrm{V}$-shaped blade design with an interior angle of 60 was analysed at a velocity of $12.6 \mathrm{~m} / \mathrm{s}$. As perceived earlier, the stagnation of the air flow on the inner side of the blade has resulted in the drop in velocity (Figure 3b).

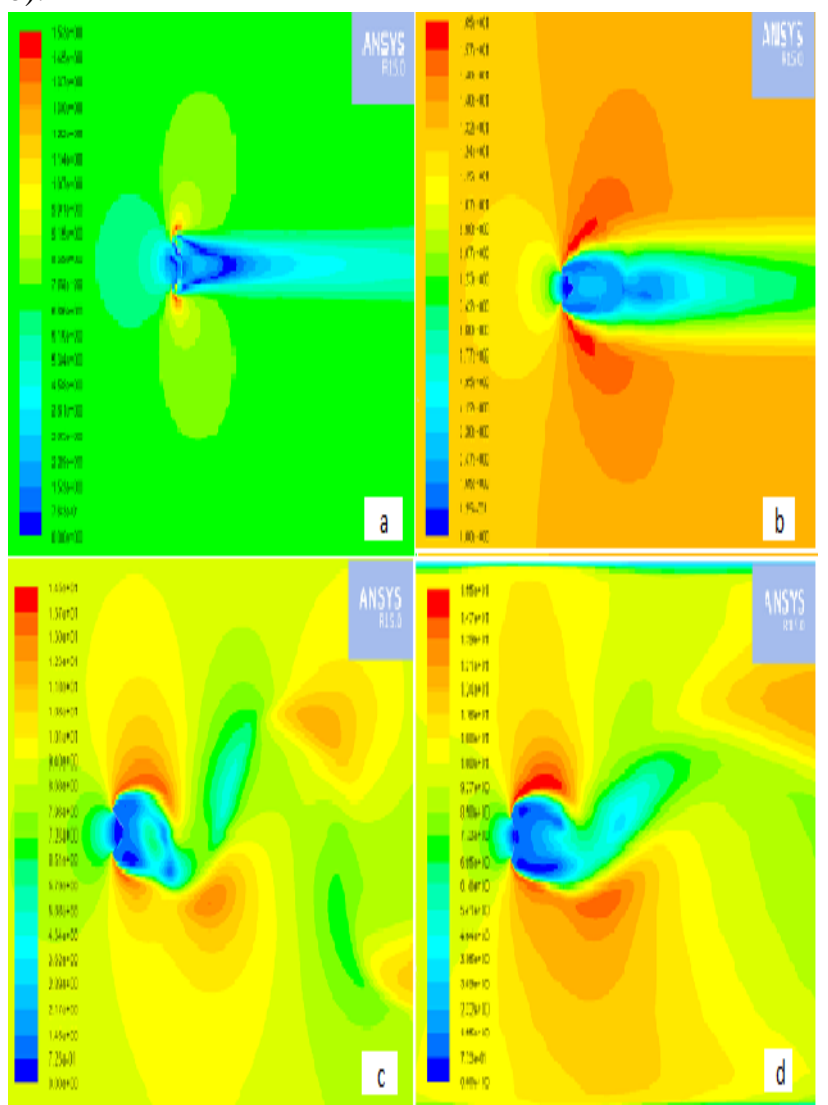

Fig. 3. Velocity Contours (a) C-shaped blade, (b) $\mathrm{V}$-shaped $60^{\circ}$ blade, (c) V-shaped $90^{\circ}$ blade, (d) V-shaped $120^{\circ}$ blade.

The wake region extends for a longer distance behind the blade. The tip speed of the blade goes up to $16.5 \mathrm{~m} / \mathrm{s}$. The V-shaped blade design with an interior angle of $90^{\circ}$ was analyzed at a velocity of $8.8 \mathrm{~m} / \mathrm{s}$. It can be clearly observed that a von-Karman vortex is created at the rear side of the blade (Figure 3c). These swirling vortices are created as a result of flow separation caused as the air flows around a bluff body [21-23]. The highest tip speed attained by the blade is $13.7 \mathrm{~m} / \mathrm{s}$.

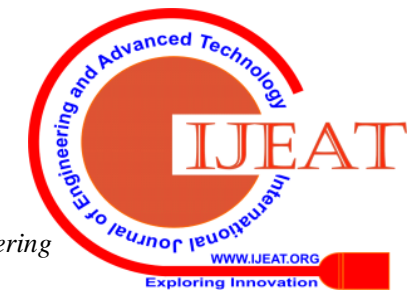


The V-shaped blade design with an interior angle of 120 was analyzed at a velocity of $10 \mathrm{~m} / \mathrm{s}$. Irregular vortices is formed behind the blade (Figure 3d). The irregularities may be due to the flow separation at the blade tips. With the increase in the interior blade angle, the amount of air accumulated on the front side of the blade decreases. Therefore sufficient amount of difference in the forces is not achieved resulting in the lower blade performance. The tip speed of this design is $15.5 \mathrm{~m} / \mathrm{s}$.

\section{Pressure Contour}

The pressure contours of the C-shaped blade design indicate a high pressure zone with a maximum pressure of 39.6 $\mathrm{Pa}$ on the inner side of the blade and low pressure zone with the least pressure of $-34.1 \mathrm{~Pa}$ on the rear side of the blade (Figure 4a). Behind the blade tips, a wake region with very low pressure is formed due to acceleration of the air flow.

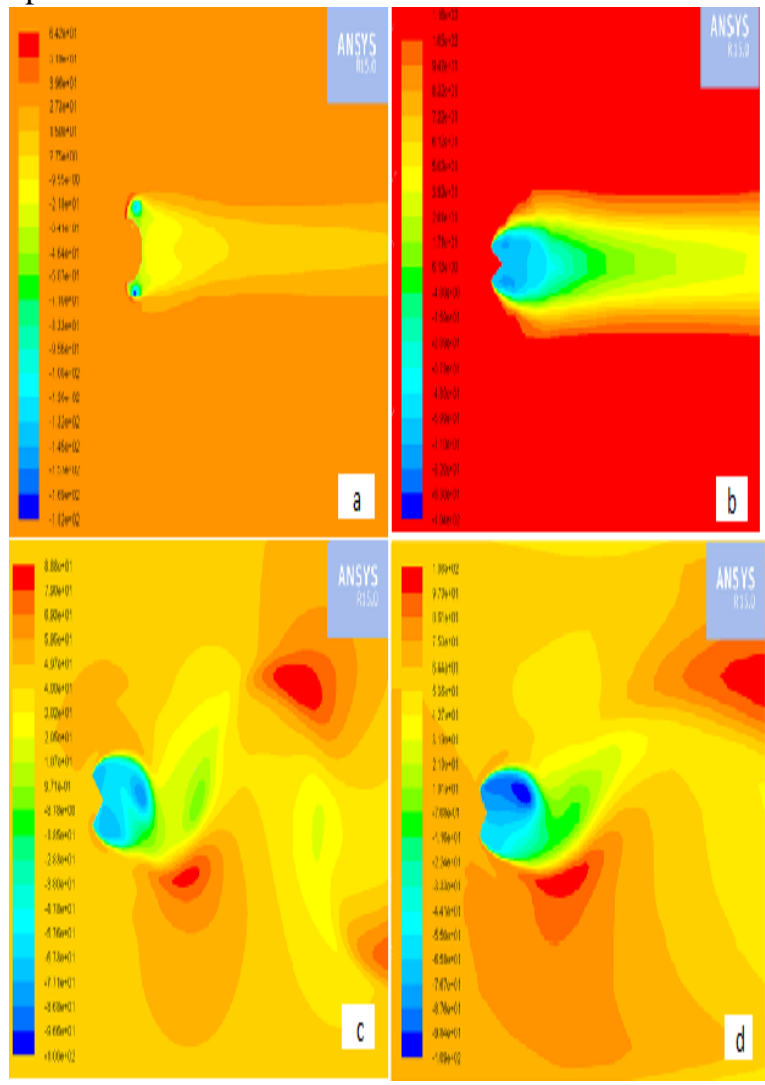

Fig. 4. Pressure contours (a) C-shaped blade, (b) V-shaped $60^{\circ}$ blade, (c) V-shaped $90^{\circ}$ blade, (d) V-shaped $120^{\circ}$ blade.

\section{WIND TUNNEL TEST}

All the blade designs have been tested in a low subsonic wind tunnel to determine its cut-in speed and performance at various wind velocities. The models were fitted firmly inside the test section with the help of the aluminium frame. It was ensured that the turbine shaft is free to rotate without any kind of obstruction. The two main characteristics of the wind turbine that were measured were its rotational speed (in terms of $\mathrm{rpm})$ and torque $(\mathrm{N} \mathrm{cm})$ produced at various wind velocities. The rpm of the turbine was measured using the non-contact laser tachometer and the torque using the TQ 8800 torque meter. Table 1 represents the cut-in speed and rpm at that speed for the different blade designs.
Table-1: Cut-in speed and cut-in rpm of the blade designs

\begin{tabular}{|c|c|c|}
\hline Blade Design & $\begin{array}{r}\text { Cut-in Speed } \\
(\mathbf{m} / \mathbf{s})\end{array}$ & Cut-in RPM \\
\hline C-shaped & 3.7 & 143.4 \\
\hline Triangular & 5.4 & 79 \\
\hline $60^{\circ} \mathrm{V}$-shaped & 4.6 & 83.2 \\
\hline $90^{\circ} \mathrm{V}$-shaped & 4.6 & 100.7 \\
\hline $120^{\circ} \mathrm{V}$-shaped & 5.4 & 94.8 \\
\hline
\end{tabular}

\section{RESULT AND DISCUSSION}

With the help of the wind tunnel experiments, the capacity and the efficiency of the different blade designs can be determined. The C-shaped two-bladed turbine was found to have the lowest cut-in speed of $3.7 \mathrm{~m} / \mathrm{s}$. Figure 3 represents the amount of power produced by the various blade designs at varying wind speeds. It can be inferred from the graph that the C-shaped two-bladed turbine and V-shaped blade with an interior angle of 60 produce almost equal amounts of power. At wind speeds between $10 \mathrm{~m} / \mathrm{s}$ and $14 \mathrm{~m} / \mathrm{s}$, the $60^{\circ} \mathrm{V}$-shaped blade has been noticed to produce a slightly higher amount of power.

The ability of a wind turbine to extract kinetic energy from the wind is represented through coefficient of power (Cp) which can also be termed as efficiency. From the plot between wind speed and coefficient of power for different blade designs (Figure 4), it can be understood that the C-shaped two-bladed turbine has the highest efficiency at wind speeds up to $10 \mathrm{~m} / \mathrm{s}$ and above $14 \mathrm{~m} / \mathrm{s}$ whereas the $60 \mathrm{~V}$-shaped turbine performs better in the wind speed range of $10 \mathrm{~m} / \mathrm{s}$ to $14 \mathrm{~m} / \mathrm{s}$. The coefficient of power of the $60 \mathrm{~V}$-shaped turbine reaches a peak of 0.09 at $12.6 \mathrm{~m} / \mathrm{s}$ beyond which it fluctuates due to the turbulence that forms at high wind speeds which

The $120^{\circ} \mathrm{V}$-shaped turbine displays the least performance in comparison to all the other blade designs. The maximum coefficient of power of this blade design is 0.0107 at $2.9 \mathrm{~m} / \mathrm{s}$. This might be due to the fact that with the increase in the interior angle, the overall surface area of the blade increases which results in the reduction of the advancing blade's capability to capture the drag force. Meanwhile, the amount of drag experienced by the returning blade increases resulting in the low rotational speed and hence an overall decrease in power extraction. 


\section{Performance Augmentation of V- Bladed Savonius Wind Turbine}

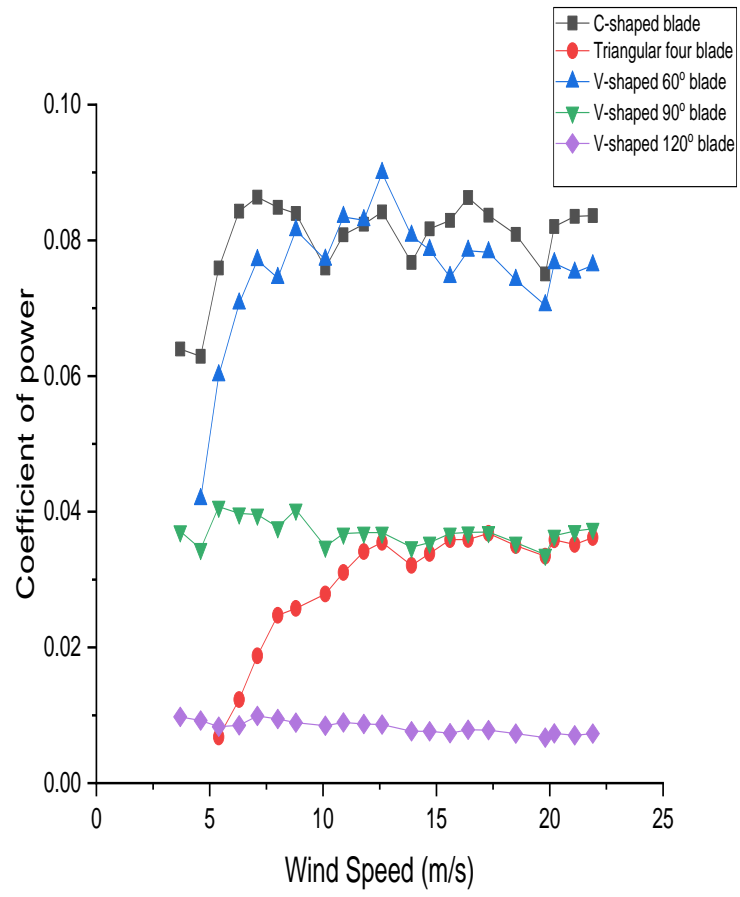

Fig. 5. Plot between Wind Speed and Coefficient of Power for different blade designs

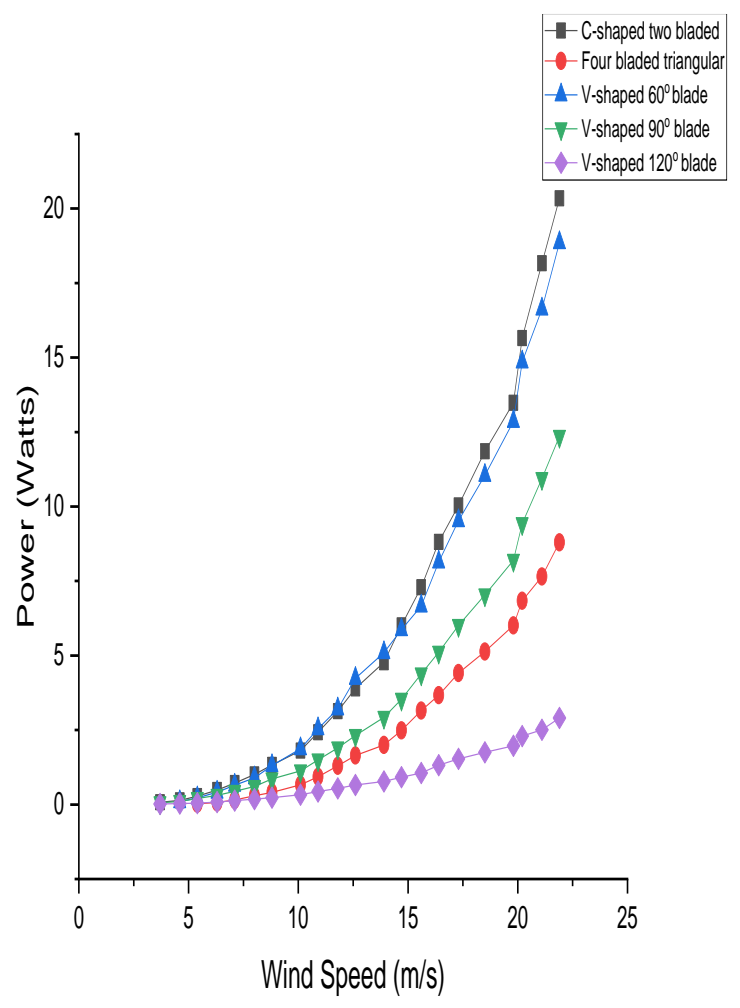

Fig. 6. Plot between Wind Speed and Power for different blade designs

\section{CONCLUSION}

From our work the following results are drawn,

- The V-shaped blade with an interior angle of $60^{\circ}$ has the highest coefficient of power of 0.09 at $12.6 \mathrm{~m} / \mathrm{s}$.

- The C-shaped two-bladed turbine has the lowest cut-in speed of $3.7 \mathrm{~m} / \mathrm{s}$.
- With the increase in the interior angle of the V-shaped blades, the performance of the turbine decreases.

- Among the five blade designs, the V-shaped blade with an interior angle of $120^{\circ}$ has the lowest coefficient of power of 0.0107 .

- When compared to the conventional blade design, the V-shaped blade with an interior angle of $60^{\circ}$ has the capacity to produce more power at wind speeds ranging from $10 \mathrm{~m} / \mathrm{s}$ to $14 \mathrm{~m} / \mathrm{s}$.

\section{REFERENCES}

1. S. P. Hosmani, “Development Research Issn : 2230-9926,” no. 696 m, 2013, pp. 2012-2014.

2. Vishal Maurya,"Future Scope of Wind Energy in Indian," in IOSR J. Electr. Electron. Eng., vol. 10, no. 1, 2015, pp. 79-83.

3. M. Zemamou, M. Aggour, and A. Toumi,"Review of savonius wind turbine design and performance," in Energy Procedia, vol. 141, 2017, pp. 383-388.

4. M. Hadi Ali,"Experimental Comparison Study for Savonius Wind Turbine of Two \& Three Blades At Low Wind Speed, vol. 3, no. 5 , 2013, pp. 2978-2986.

5. U. K. Saha, S. Thotla, and D. Maity, "Optimum design configuration of Savonius rotor through wind tunnel experiments," in J. Wind Eng. Ind. Aerodyn., vol. 96, no. 8-9, 2008, pp. 1359-1375.

6. N. H. Mahmoud, A. A. El-Haroun, E. Wahba, and M. H. Nasef,“An experimental study on improvement of Savonius rotor performance," in Alexandria Eng. J., vol. 51, no. 1, 2012, pp. 19-25.

7. S. Acharaya, S. Hegde, and C. G. Ramachandra,"Permanent Magnet Propelled Vertical-Axis Wind Turbine," 2016, pp. 383-386.

8. A. Alaimo, A. Esposito, A. Milazzo, C. Orlando, and F.Trentacosti,"Slotted blades savonius wind turbine analysis by CFD," in Energies, vol. 6, no. 12, 2013, pp. 6335-6351.

9. S. Deshmukh and S. Charthal,"Design and Development of Vertical Axis Wind Turbine," in IRA-International J. Technol. Eng. (ISSN 2455-4480), vol. 7, no. 2 (S), 2017, p. 286.

10. H. Gad and M. H. Nasef,"A New Design of Savonius Wind Turbine : Numerical Study," no. December 2014.

11. P. Gulve and S. B. Barve,"Design and Construction of Vertical Axis Wind Turbine Ijmet (C I a E M E," in Int. J. Mech. Eng. Technol., vol. 5, no. 10, 2013, pp. 148-155.

12. N. Hettiarachchi, "Design , Fabrication and Testing of a Vawt With Wind Deflectors," no. October 2017.

13. Q. Islam, N. Hasan, and S. Saha,"Icme05-Fl-23 Experimental Investigation of Aerodynamic Characteristics of Two , Three and Four Bladed S-Shaped Stationary Savonius Rotors .," 2005, pp. 28-30.

14. A. Kadam and S. Patil, "A Review Study on Savonius Wind Rotors for Accessing the Power Performance," in IOSR J. Mech. Civ. Eng., no. September 2015, pp. 18-24.

15. J. H. Lee, Y. T. Lee, and H. C. Lim, "Effect of twist angle on the performance of Savonius wind turbine," in Renew. Energy, vol. 89, 2016, pp. 231-244.

16. M. Marini, A. Massardo, and A. Satta,"Performance of vertical axis wind turbines with different shapes," in J. Wind Eng. Ind. Aerodyn., vol. 39, no. 1-3, 1992, pp. 83-93.

17. D. A. Nikam and S. M. Kherde,"Literature review on design and development of vertical axis wind turbine blade," in Int. J. Eng. Res. Appl., no. November 2015, pp. 156-161.

18. A. S. Onawumi and S. O. Olaoye, "A Review of Savonius Wind Turbine as a Source of Energy Generation in Nigeria," in Int. J. Emerg. trends Eng. Dev., $\quad$ vol. 3, no. December 2011, pp. 325-336.

19. P. S. Shukla, P. K. Sharma, and S. A. Patil,“a Review Paper on Vertical Axis Wind Turbine for Design and Performance Study To Generate Electricity on Highway," in Int. J. Adv. Eng. Res. Dev., vol. 3, no. 12, 2018, pp. 116-122.

20. L. Song, H. Z. Liu, and Z. X. Yang, "Performance comparison for savonius type wind turbines by numerical analysis approaches," in Int. Conf. Adv. Mechatron. Syst. ICAMechS, 2015, pp. 402-407.

21. Alka Sawale, M.D. Khaleel and S. Jaswanth,"Design and analysis of winglet", International Journal of Civil Engineering and Technology, vol. 8, no. 5, 2017, pp. 842-850.

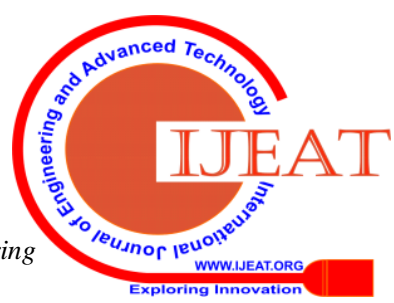


22. Eppakayala Naresh, Pinnamaneni Dileep Kumar, N. Anil Kumar and B. Nagaraj Goud,"Drag reduction over a circular cylinder", in International Journal of Civil Engineering and Technology, vol. 8, no. 8, 2017, pp. 1334-13345.

23. A. Sai Kumar and M. Ganesh,"Evaluation of effect of shape and length of spike on aerodynamics performance of supersonic axi-symmetric bodies", International Journal of mechanical and Production Engineering Research and Development, vol. 8, no. 1, 2018, pp. 133-144.

\section{AUTHORS PROFILE}

Dr. A Vivek Anand, Professor in the Department of Aeronautical Engineering, MLR Institute of Technology, Hyderabad, Telangana, India. Ph.D. specialization on Wettability and Corrosion Behavior of Micropatterned SS304 Steel.

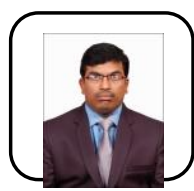

Dr. M Sathyanarayana Gupta , Professor, in the department of Aeronautical Engineering at MLR Institute of Technology, Hyderabad Telangana. Ph.D. specialization on Design and Production of Machine Tools.

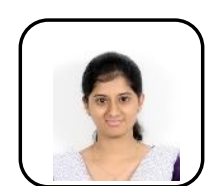

Ms. J Sahana, Student in the Department of Aeronautical Engineering, Bannari Amman Institute of Technology, Sathyamangalam, Tamil Nadu, India

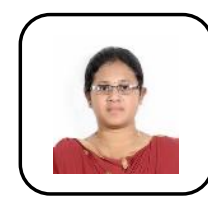

Ms. P ShanmugaPriya, Student in the Department of Aeronautical Engineering, Bannari Amman Institute of Technology, Sathyamangalam, Tamil Nadu, India

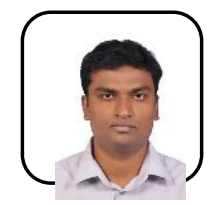

Mr. V Hariprasad, Assistant Professor in the department of Aeronautical Engineering, Bannari Amman Institute of Technology, Sathyamangalam, Tamil Nadu, India. 